\title{
Do Império à República: escrita poética e biografia em Tobias Barreto (1869-1889)
}

From Empire to Republic: poetic writing and biography in Tobias Barreto (1869-1889)

Aruanã Antônio dos Passos ${ }^{*}$

\begin{abstract}
Resumo
O trabalho analisa a escrita poética de Tobias Barreto (1839-1889) e os traços biográficos presentes em tal escrita. Para tanto, procuramos perceber as inferências entre a escrita e a expressão de sua sensibilidade poética na trajetória intelectual do sergipano. Traçamos um paralelo entre os temas de sua poesia e as possíveis conexões com sua vida privada. Dessa forma, procuramos desvelar uma dimensão de sua biografia que se expressa em sua vida intelectual onde a escrita determina o sentido e a sensibilidade é construída dialogicamente como relação de alteridade consigo mesma.
\end{abstract}

Palavras-chave: Escrita poética; Tobias Barreto; Brasil Império.

\begin{abstract}
The paper analyzes the poetic writing of Tobias Barreto (1839-1889) and the biographical features present in such writing. For this, we try to understand the inferences between the writing and the expression of its poetic sensibility in the intellectual trajectory of the sergipano. We draw a parallel between the themes of his poetry and the possible connections with his private life. In this way, we seek to unveil a dimension of his biography that is expressed in his intellectual life where writing determines the meaning and sensitivity is constructed as a relationship of alterity with itself in a dialogical way.
\end{abstract}

Keywords: Poetic writing; Tobias Barreto; Brazil Empire.

\section{O combativo Tobias Barreto na aurora da República}

O Brasil do último quartel do século XIX foi profundamente marcado por uma efervescência cultural e intelectual, determinante e própria da chamada crise do Estado imperial. Como assinala Alfredo Bosi, a partir de 1868, a estabilidade do Segundo Império foi abalada, definitivamente, e sua contestação culminaria com a Abolição da escravatura, a proclamação da República, a urbanização e industrialização iniciais, além da adoção de políticas imigratórias como alternativa social ao trabalho livre e à

\footnotetext{
* Doutor em História pela Universidade Federal de Goiás (UFG). Professor da Universidade Tecnológica Federal do Paraná (UTFPR).
} 
colonização de várias regiões de nosso território - destaque especial para os contingentes populacionais que se fixaram no sul e sudeste do país (BOSI, 1992, p. 222).

No plano das ideias, o nódulo central de ordenação das apropriações estrangeiras e suas adaptações em nome de um projeto nacional (político e cultural) de desenvolvimento civilizacional é a necessidade de definição de uma identidade, ou ainda caráter nacional. Desenvolvimento, aqui, entendido no sentido próprio do século XIX, ou seja, relacionado às ideias de progresso e evolução:

Entre projeções futuristas e revalorizações do passado, escritores do Brasil na passagem de século tentavam fazer o que o modernismo, depois, adotaria como programa: redescobrir o país. Confiança extrema no progresso técnico ou consciência das heranças que pesavam em nosso desconcerto nacional, eis as duas visões que conviviam num mesmo dilema (HARDMAN, 1992, p. 289).

Diversos movimentos culturais e sociais demarcavam a paisagem de fundo dessas manifestações intelectuais. É a época da predominância da influência da cultura francesa no país, do desenvolvimento da imprensa, da luta contra a escravidão, contra a monarquia e contra o atraso do país em relação ao resto do planeta, principalmente, o mundo chamado "civilizado": eminentemente, o cenário europeu. O Nordeste ${ }^{1}$ era um importante centro de recepção e ligação do Brasil com o mundo. É nesse contexto que um grupo de intelectuais liderados por Tobias Barreto (1839-1889) ${ }^{2}$ e Sílvio Romero (1851-1914) fundam, na Faculdade de Direito do Recife, a chamada "Escola de Recife", na capital de Pernambuco, a partir da década de 1860. Utilizamos o termo "Escola" como frequentemente aparece nos estudos sobre o movimento, no entanto, é questionável a aplicação de uma definição estrita da noção de "Escola" para esse grupo

\footnotetext{
${ }^{1}$ A região do Nordeste brasileiro, no século XIX, recebia a alcunha de "Norte". O termo "Nordeste", como demostrou Durval Muniz de Albuquerque Júnior, é uma invenção que ganha corpo ao longo do século XX. Portanto, nosso uso desse termo não negligencia esse processo, apenas o faz corrente para melhor delimitação e entendimento, já que hoje "Nordeste" se encontra consolidado. Cf: ALBUQUERQUE JÚNIOR, 2009, p. 33 e ss.

2 Tobias Barreto de Menezes nasceu em Campos, Sergipe, em 7 de junho de 1839 e morreu no Recife, Pernambuco, em 26 de junho de 1889. Em 1862, Tobias Barreto muda-se para o Recife, ingressando na Faculdade de Direito, em 1864, e concluindo o curso no ano de 1869. Voltando, então, a viver no interior. A partir de 1871, passa a morar em Escada (interior de Pernambuco), atuando como advogado, sem perder o contato com a vida intelectual do Recife. Permanece em Escada até 1881, quando presta concurso para professor da Faculdade de Direito em Recife. Aprovado em primeiro lugar, toma posse como professor substituto em 1882. Morre em Recife em 1889. Publicou em vida: Ensaios e Estudos de Filosofia e Crítica (1875); Brasilien, Wie es Ist (1876); Ensaio de Pré-História da Literatura Alemã (1879); Um Discurso em Mangas de Camisa (1879); Filosofia e Crítica (1879); Estudos Alemães (1879); Algumas Idéias sobre o Chamado Fundamento do Direito de Punir (1881); Menores e Loucos (1884); Discursos (1887); Questões Vigentes de Filosofia e de Direito (1888).
} 
de estudantes e professores do movimento. Como apontamos, a corrente de pensamento, em um primeiro momento, recebeu a alcunha pejorativa de "Escola teuto sergipana", e depois se estabelece o termo Escola do Recife, que passa a ser identificada com a Faculdade de Direito.

Os principais nomes ligados à Escola foram: Sílvio Romero, Capistrano de Abreu, Graça Aranha, Artur Orlando, Clóvis Bevilácqua, Martins Júnior, Faelante da Câmara, Oliveira Teles, Sampaio Leite, Augusto Franco, Urbano Santos, Abelardo Lobo, Vitoriano Palhares, José Higino Duarte Pereira, Araripe Júnior, Gumercindo Bessa, João Carneiro de Sousa Bandeira ${ }^{3}$. Dentre os objetivos da "Escola" - certamente difusos, já que não houve ordenamento sistemático de um programa de ação - figurava o desejo de afirmar o Nordeste brasileiro como centro intelectual tão importante quanto São Paulo e Rio de Janeiro.

Desse "projeto" intelectual, nascido na Escola de Direito do Recife, esses intelectuais construíram certa projeção no que tange à cultura e ao caráter nacional, formando um verdadeiro projeto de nação: "a Faculdade de Direito da capital pernambucana, por ser à época o único estabelecimento de ensino superior no Nordeste, recebia alunos das diversas províncias daquela região. Essa circunstância permitiu a irradiação das ideias da Escola do Recife, formando-se alguns núcleos de seus partidários no Ceará, em Sergipe e na Bahia” (PAIM, 1997, p. 47). Do ponto de vista das ideias: "A Escola do Recife, da qual emergiram os chamados culturalistas brasileiros, inaugurou o debate livre de idéias no Brasil, de forma sistemática e aberta a todas as correntes filosóficas. O desenho da Escola está marcado basicamente pelas formas de pensar de suas duas maiores expressões: Tobias Barreto, seu fundador, e Sílvio Romero" (NASCIMENTO, 1999, p. 155).

Analisamos a produção poética de Tobias Barreto na sua perspectiva biográfica, sem, necessariamente, revelar traços de sua psicologia ou elementos de seu

\footnotetext{
${ }^{3}$ Ver C $f$ : FILHO, Evaristo de Moraes. Medo à Utopia: o pensamento social de Tobias Barreto e Sílvio Romero. Rio de Janeiro: Nova Fronteira: 1985. p. 47-48. Ainda segundo Coutinho: "Para começar, o termo 'escola' designa um conceito suficientemente difuso, sem limites precisos como os que são definidos, por exemplo, por Igreja, Seita ou Partido. Sendo as escolas de fato conjuntos difusos, poder-seia definir campos semânticos, com seus gradientes de intensidade, mensuráveis pela escolha arbitrária de variáveis preferidas. Em uma escola, ao contrário de uma igreja como a positivista, ou a epicurista, invariantes no tempo e no espaço, os componentes, os fiéis, preservam as personalidades, as inclinações próprias e individuais, de maneira que se pode reconhecer divergências internas e efeitos de influência remota. Muito ao contrário das igrejas, seitas e partidos, nas escolas as divergências não causam desmembramentos ou heresias promotoras de rupturas insanáveis, tão bem conhecidas nos primeiros" (COUTINHO, 1988, p. 27). Cabe ainda observar que Clóvis Beviláqua utiliza o termo "escola teutosergipana", mas não com o sentido pejorativo de Taunay (BEVILÁQUA, 1883, p. 45).
} 
comportamento combativo, mas, sim, compreender o conjunto de poesias como criação significativa de uma trajetória marcada pelo romantismo literário e pela posterior adesão ao germanismo, especialmente, na filosofia. Assim, haveria certa continuidade entre o seu romantismo e a sua posterior defesa aguerrida do pensamento alemão (já na maturidade de seu pensamento)? Sabemos que os alemães exploraram a exaltação ao passado e aos valores culturais ("raízes") nacionais no Romantismo, mesmo elemento constitutivo da historiografia oitocentista de inspiração romântica que edificou a construção dos estados nacionais na Europa.

Avaliação estética à parte, de modo específico, centramos esse trabalho a testar os limites da relação entre fragmentos biográficos e a escrita poética de Tobias Barreto, o mestre referencial ${ }^{4}$, perene ponto de partida de definição da Escola do Recife e de doutrinação dos jovens, futuros ícones da República nos campos do direito, da política e da educação. Segundo descrição de Paulo Mercadante, sobre a tensão entre as características pessoais de Tobias e sua trajetória, encontramos a revelação de um aspecto da personalidade combativa do sergipano:

\footnotetext{
Nesse contexto inclusive Tobias Barreto de Meneses, nordestino pobre, mulato ressentido, didacta em latim e jurisprudência, diletante nas demais áreas do saber. Sua trajectória é curta e fascinante, apenas cinquenta anos de vida. Sua versatilidade não é arbitrária é calculada, talvez, e parece obedecer a um plano.

Nele conjugam-se a febre de demolir e ânsia em semear. Atirou-se a polémica sem a formal compostura de quem sabe divergir, manchando-lhe o mal gosto, com muita frequência. $\mathrm{O}$ rigor dos argumentos. Porém a justiça se faça: no bom combate em que peleja jamais deixa de plantar no solo revolvido as sementes de novas idéias.

Que circunstâncias geraram esse D. Quixote, mal criado e sincero?

Nasceu numa pequena província, filho de um notário modesto, boêmio e liberal (MERCADANTE, 1991, p. 35).
}

Em um primeiro momento, analisamos sua obra poética, contrastando-a com os principais contornos biográficos construídos pela crítica ulterior, que pouca luz lançou sobre sua obra poética. O momento que coincide com o jovem Tobias Barreto e sua formação intelectual relega sua produção poética a uma fase de maturação acrítica em sua trajetória intelectual. A imagem se modifica se colocarmos em perspectiva o fato de que essas poesias abriram espaço nos jornais do Recife e no interior do Estado para o conhecimento de seu pensamento e obra. Em outras palavras, além do conteúdo estético

\footnotetext{
${ }^{4}$ Alfredo Bosi reduz a Escola às figuras de Tobias e Romero, tamanha importância creditada aos dois nomes: "É à 'Escola do Recife', isto é, a Tobias Barreto e a seu discípulo fiel, Sílvio Romero, que se deve a primeira transposição dessa realidade em termos de consciência cultural" (BOSI, 2007, p. 165).
} 
que replicava elementos do romantismo, como o ideal de belo, partimos da hipótese de que esse conjunto de poemas revela um substrato de seu pensamento, ainda que carregado pela sensibilidade do amor, da desilusão, da perda.

\section{Dias e Noites: fragmentos biográficos de uma literatura "trivial"5}

Suas poesias foram reunidas e publicadas, em 1881, no Rio de Janeiro, com o título de Dias e Noites (ROMERO, 1980, p. 1185). A edição de que nos valemos é a publicação póstuma dirigida e organizada por Sílvio Romero e lançada em 1903, pela editora Laemmert \& Cia, do Rio de Janeiro e de São Paulo. O livro reúne poesias que cobrem o período de 1854 a 1888 e organizadas em quatro partes: a primeira intitulada “Geraes e Naturalistas" (49 poemas), a segunda "II - Patrioticas" (19 poemas), seguida de "III - Estheticas" (21 poemas) e "IV - Amorosas" (38 poemas). O livro ainda contém um apêndice com um diálogo entre os quatro personagens, intitulado "A mulher e o amor".

Antes da análise dos poemas, vale ressaltar que não nos valemos aqui de uma crítica estilística minuciosa. Não procuramos perceber de que forma Tobias Barreto pode ser igualado aos "grandes" nomes da poesia oitocentista, muito menos enquadrá-lo em algum cânone literário. Interessa-nos a percepção, em seus poemas, de traços biográficos e de elementos constitutivos de sua trajetória intelectual até aquele momento. Dessa forma, percorremos o limite de um caminho que pode ser considerado delicado: a expressão do sensível como indissociável das diversas manifestações de racionalidade, ainda que consideremos que nos oitocentos, "os poetas tiveram principalmente por musa o patriotismo, o entusiasmo estético e o amor" (ROMERO, 1980, p. 1185). Tais elementos, obviamente, carregados de racionalidade própria e consciência de papel social e efeito no espaço público, principalmente, em um contexto de afirmação das nacionalidades.

Se a consciência social e o messianismo podem ser tomados como características marcantes da autodefinição do intelectual, as formas particulares de realização de tais traços variam no tempo e se alteram em função do regime político com o qual ele interage. A influência da atividade intelectual tem a ver com o grau de diferenciação dos papéis intelectuais, com o grau de pluralismo do sistema ideológico e com o grau de flexibilidade da tradição (OLIVEIRA, 1999, p. 85).

\footnotetext{
${ }^{5}$ O termo "trivial” pertence a parte dos críticos da obra literária de Tobias. Cf: MARTINS, 1979.
} 
Dessa maneira, se entendermos que a escrita poética coloca em cena uma série de sentimentos e sensibilidades que são próprias e específicas do poeta - obviamente não descartando a capacidade intuitiva da escrita poética como dissociada de uma experiência em torno do objeto ou sentimento a ser poetizado -, é possível compreender o poema como detentor de fragmentos de uma vida? No que se refere a Tobias, sua verve poética é exaltada por diversos comentadores de sua obra a exemplo de figuras do porte de Clovis Beviláqua. De modo geral, sua poesia sofrera forte influência, como já pontuamos, do romantismo de Victor Hugo, que ele descobrira em seus anos de estudo em Recife e pela sua passagem por Salvador. Hermes Lima reconstitui o quadro contextual desse tempo de formação:

Preferia a Biblioteca Pública aos professores. Ali passava o melhor do seu tempo, lendo os românticos, deslumbrando-se com Victor Hugo, que é, verdadeiramente, a sua grande, a sua máxima descoberta na Bahia. Pela voz do poeta, o rapaz humilde e sonhador do sertão de Sergipe entra a participar do drama do mundo, dos seus anseios, da sua inquietação. O poeta lançavalhe no coração a semente das futuras estrofes condoreiras. Sua alma recebia o pólen romântico para vingar, na exaltação da personalidade e do espírito de liberdade, as resistências conservadoras do meio (LIMA, 1957, p. 6).

E, à forte presença de Victor Hugo nesse momento de sua vida, Tobias dedica um dos poemas de Dias e Noites, datado de 1864 e, justamente intitulado, "Victor Hugo"6. No que concerne ao seu legado poético e literário, taxam-lhe de trivial e sensualista $^{7}$. Para alguns, sua obra marca uma pequena nota de rodapé do condoreirismo, em muito superado em qualidade estética e impacto social da obra de Castro Alves, mais jovem que Tobias, poeta, inclusive, que chegou a se envolver em polêmica, apesar da amizade entre ambos:

\footnotetext{
${ }^{6}$ Tobias traduz um poema de Victor Hugo incluído em Dias e Noites. O poema intitulado "Um pouco de música" data de 1865.

7 José Veríssimo, que se envolveu em polêmica com Sílvio Romero, em seu clássico História da Literatura Brasileira, define a obra literária de Tobias Barreto nos seguintes termos: "Muito menor foi o renome e a influência de Tobias Barreto como poeta do que como pensador. Eclipsou-lhos Castro Alves, seu feliz êmulo no condoreirismo e seu triunfante rival em toda poesia. O lirismo de Tobias Barreto, no que tem de melhor, é em suma da mesma espécie do comum lirismo brasileiro, amoroso ou antes namorado, sensual, dolente, abundante em voluptuosidades ardentes e queixumes melancólicos. Se alguma coisa o distingue é, de um lado, o tom oratório, ainda épico, em que oscila entre as extravagâncias dos Voluntários Pernambucanos e quejanos poemas e os belos rasgos do Gênio da Humanidade; de outro, a nota popular simples, vulgar, mesmo trivial, que às vezes lhe dá a cantiga um sainete particular e, ocasionalmente encantador" (VERÍSSIMO, 1998, p. 318).
} 
$\mathrm{Na}$ crista daquela onda vinham duas figuras de primeira grandeza: Tobias e Castro Alves. Cada qual possuía o seu bando, a sua facção, a sua côrte. Mas, se, no fundo, não havia problemas sérios a dividi-los, se todos adoravam a liberdade, combatiam a escravidão, versejavam pelo diapasão hugoano; se todos a todos empolgava a admiração pelos mesmos heróis e valores, os dois chefes eram, todavia, diferentes como origem social, como temperamento, como molde de espírito. Castro, olímpico, belo, ardendo na mais pura flama poética que ainda palpitou em nosso país. Tobias, mestiço, desajustado, mais velho, mais estudioso e preparado que o rival, contrastando com o gênio poético do cantor dos escravos o seu já forte talento de crítico e polemista. Agrupavam-se em torno de um ou de outro, movidos por simpatias pessoais, móvitos afetivos e extremavam-se na admiração por atrizes celebres do tempo (LIMA, 1957, p. 9-10).

A polêmica com Castro Alves tinha uma ambientação social que nos revela a propensão de Tobias para os embates de ideias que se tornariam uma das tônicas de sua vida pública: "Naquela cidade pacata, de escassos divertimentos, a Academia e o teatro formavam os dois pólos em que se concentrava a atividade espiritual dos estudantes" (LIMA, 1957, p. 10). No entanto, a rixa não acabaria bem, se encerrando com o rompimento, em definitivo, da amizade entre os dois: "O tempestuoso rompimento verificou-se em 1866. Para Castro Alves, a vida corria descuidada e feliz. Para Tobias, era já um fardo que ele tinha de suportar com as próprias forças. O sentimento desse contraste não deve ter sido alheio ao tom desabrido que Tobias imprimiu, de sua parte, à polêmica que, entoa, entre os dois antigos camaradas se travou" (LIMA, 1957, p. 11).

Mas, no campo poético, o legado de Castro Alves assumiria lugar ímpar em nossa poesia, ao contrário dos poemas de Tobias Barreto. Mas a que isso se deve? Silvio Romero responde à questão recorrendo ao contexto externo à própria poesia. Segundo Romero: “(...) Castro Alves, discípulo muito aproveitado, mas sem a intuição filosófica, o sentimento exato e a correção plástica do mestre, passando pelo Rio de Janeiro, onde teve ruidoso acolhimento, foi prosseguir o seu curso em São Paulo, fez-se lá ouvir e criou asseclas, que depois proclamaram a nossa poesia hugoniana como um rebento daquele solo (...)" (ROMERO, 1980, p. 1185).

Podemos afirmar que constitui um caráter geral de sua poesia a construção de imagens poéticas de extremo efeito metafórico, ainda que fiquem visíveis os limites e possibilidades do gênero exercitado pelo poeta ${ }^{8}$. Esse efeito calcado na construção de imagens fundamentadas na noção de belo, inspirada na beleza da própria natureza, produz no leitor um misto de sentidos, os quais, por vezes, não se consegue distinguir entre o sentimento descrito no poema e a autenticidade da experiência sensível, ou se é

\footnotetext{
${ }^{8}$ Na definição de Carlo Ginzburg: "Um gênero é definido por uma série de características que implicam ao mesmo tempo restrições e possibilidades" (GINZBURG, 2007, p. 191).
} 
apenas o brilho fosco do exercício estético da palavra pela palavra. O próprio Romero destaca o esvaziamento dessa posição estética, que segundo ele, pela "falta de sentimentos e de idéias foi suprimida pela fantasmagoria de uma linguagem empolada e gongórica" (ROMERO, 1980, p. 1185). em muito isso decorre do fato de que "Tobias Barreto e Castro Alves, passando para os seus discípulos, ostensivos ou não, o estilo se exagerara, tornando-se uma maneira áspera de poetar..." (ROMERO, 1980, p. 1185). Daí a razão de o romantismo de Tobias, fruto da influência de Victor Hugo, soar, por vezes, trivial e irônico, ainda que se perceba que seu ideal de beleza seja uma “concepção de uma imitação criadora" (MACHADO, 2006, p. 13) que remonta aos gregos antigos. Outro elemento importante de sua poesia é o uso da ironia, verdadeira constante nos poemas do sergipano. Seja a ironia por sua condição de mulato, seja pelos modismos de sua época que encontraram tinta em sua pena, como na linguagem popular retratada em "Chapa", poema de 1880:

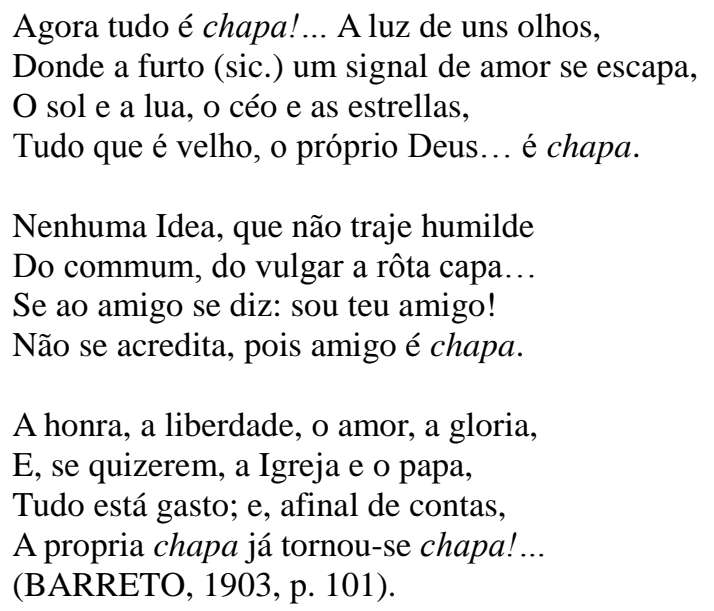

Essa veia irônica reforça e condiz com uma característica temática da escrita poética de Tobias, destacada por Hermes Lima: a recorrência de temas ligados à vida noturna, festas, bailes e rodas de violão. E é claro que sua própria condição de mulato era mote para a sua verve irônica como em "Papel queimado" (1873). Já em "A escravidão" (1868) e "Ignorabimus" (1880), temos outro panorama. Em um primeiro momento, a crítica ao naturalismo com que a escravidão era entendida como uma forma social legitimada pela história e pelo Criador. No segundo poema, mais próximo de uma crítica da escravidão, o tom endurece: 
Que se chama a escravidão.

Para fazer homens livres,

Para arrancal-os do abysmo,

Existe um patriotismo

Maior que a religião

Se não lhe importa o escravo

Que a seus pés queixas deponha,

Cobrindo assim de vergonha

A face dos anjos seus,

Em seu delírio Ineffavel,

Praticando a caridade,

Nesta hora a mocidade

Corrige o erro de Deus!...

(BARRETO, 1903, p. 96).

Ignorabimus (1880)

Quanta illusão!... O céo mostra-se esquivo

E surdo ao brado do universo inteiro...

De duvidas cruéis prisioneiro,

Tomba por terra o pensamento altivo.

Dizem que o Christo, o filho de Deus vivo,

A quem chamam também Deus verdadeiro,

Veio o mundo remir do captiveiro,

E eu vejo o mundo ainda tão captivo!

Se os reis são sempre os reis, se o povo ignavo

Não deixou de provar o duro freio

Da tyrannia, e da miséria o travo,

Se é sempre o mesmo engodo e falso enleio,

Se o homem chora e continúa escravo,

De que foi que Jesus salvar-nos veio?..

(BARRETO, 1903, p. 70).

Esses fragmentos poéticos são de uma literatura considerada trivial pelos críticos literários e os momentos biográficos que desvelam se cruzam em um mosaico, no qual o jovem Tobias confirmava sua identidade frente ao ímpeto de suas paixões e às imposições sociais que condicionavam seu destino. Ainda que tarde para o contexto de seu tempo, aos 25 anos, ele iniciaria o curso acadêmico no Recife e sua trajetória intelectual se desviaria da literatura para a ciência jurídica, ainda que sua produção poética tenha continuado durante seus estudos, ressaltando uma das características de sua trajetória intelectual: a inclinação para a mudança e o gosto pela novidade.

\section{Da vida que se escreve, do sensível que se projeta}

Tobias Barreto teve dois momentos distintos em sua vida amorosa: a paixão por Leocádia Cavalcante e, posteriormente, seu casamento com Grata Mafalda dos 
Santos, em 11 de fevereiro de 1869. Em Dias e Noites, encontramos 22 poemas dedicados à Leocádia e apenas 6 dedicados à sua mulher com quem casara anos após o término com a paixão da juventude. Nas palavras de Hermes Lima: "A primeira, dolorosa humilhação que sua condição social lhe reservava ocorreu em 1868. Havia algum tempo, apaixonara-se por Leocádia Cavalcante, flor da aristocracia pernambucana, e a quem conhecera como professor de um dos seus irmãos. Fora um grande amor que lhe enchera a alma de sonhos e de poesia" (BARRETO, 1903, p. 12). A ela, Tobias dedica palavras de amor de tamanha profundidade que marcam todo o movimento dos enamorados, que vai de 1865 - o poeta tinha, então, 26 anos - até o ano de 1867. Segundo Sílvio Romero:

Pondo de parte pequenos e inofensivos galanteios, dirigidas a diversas belezas pernambucanas, teve ele dous profundíssimos amores, que o dominaram por completo. O primeiro com a lindíssima Leocádia Cavalcanti e levou-o quase às portas do suicídio. Desde que a viu, sentiu-se subjugado. $\mathrm{Na}$ qualidade de professor dum dos irmãos da encantadora moça, travou relações com a sua família, freqüentou-lhe a casa e teve repetidos ensejos de a ver, de a conversar e deixar-se submeter de todo ao jugo de cruel paixão. (ROMERO, 1980, p. 1223).

Destacamos o momento do apaixonar-se registrado nos fragmentos a seguir dos poemas "Penso em ti" e "Ideia":

\section{Penso em ti}

(A. L. C. - 1865)

Perdôa, se nas horas que se embebem

No coração mais cheias de amargura,

Mais pesadas de amor e de saudade,

Penso em ti... do teu seio moduloso

Sinto a onda empolada em ânsias doces

Quebrar-se junto a mim.

(BARRETO, 1903, p. 96)

$$
\text { Ideia }
$$

(A. L. C - 1865)

Amo-te muito. Não temas

Que possa dizel-o. Espera...

Comtigo a sós eu quizera

Beijar as mãos do Senhor;

No ninho das rolas castas,

No calix das flores puras

Guardar as nossas ternuras,

O nosso morrer de amor. (...)

(BARRETO, 1903, p. 227).

Leocádia passa a ser a personificação da musa inspiradora e, nesses poemas, a manifestação da musa não rompe com os padrões literários do romantismo. A musa, que 
é a manifestação do sagrado, também aparece em "Suprema Visio (A. L. C. - 1866)". Ela é a própria manifestação na natureza do sagrado, do divino e da pureza virginal em Leocadia de 1866:

\footnotetext{
Livro de luz em que o Senhor medita E ás mãos dos anjos não é dado abrir, Onde as estrellas aprenderam juntas Com as rozas puras a chorar e a rir, Alma que serve de alimento ás flores, De cuja essência a creação trescala, Ingênua e cândida, escutando em sonhos, A voz da santa que do céo vos falla...

Vós sois na terra a encarnação brilhante Do sacro amor que a vossos Paes adita, Rútila estrophe de um poema d'oiro, Livro de luz em que o Senhor medita... Lagrima d'alva que no seio cálido Da nuvem rubra vos deixou cahir, Pagina alvíssima em que Deus escreve E ás mãos dos anjos não é dado abrir... (BARRETO, 1903, p. 235).
}

A paixão se estende por todo o ano de 1866. Os versos de "Amar" (1866) e "Consente" (1866) marcam o período. Em 1867, a paixão encontra resistência nas convenções sociais e os amantes parecem se distanciar. Segundo Romero, Tobias pensara em se casar com Leocádia, mas o pai da moça fora contra. Era a negação da família de Leocádia em aceitar a condição de mulato pobre de Tobias. Em "Tão longe assim...", o poeta declara: "tudo era morto de soffrer por ti...". E os versos de "Dizeme sempre (A. L. C. - 1867)" expressam esse distanciamento:

\footnotetext{
Que te custa uma phrase, um consolo Para o meu coração, que padece, Como afago pisar sobre a juba Do leão, que a teus pés adormece?

Que te custa enganar-me fallando Se a tua alma por mim não suspira? Quero ouvir-te dizer que me amas, Inda mesmo que seja mentira!... (BARRETO, 1903, p. 254)
}

O sentimento de distanciamento se reforça nos primeiros versos de "Oh! Isto mata (A. L. C. - 1867)": "Não tenho forças para tanta lucta,/ Lucta d'archanjo, que, se mais um raio/ Mandas que eu fuja, que não mais te adore?/ Temes que um sonho revelado seja? /Queres que eu morra, que não te veja mais? /Pois bem; não temas; fugirei de ti" (BARRETO, 1903, p. 255). Já os poemas "Malévola", "Não falleis de 
mim...", "Sê meiga e terna", "Porque me feriste", todos de 1867, marcam um arco de ação que vai do amor romântico à desilusão mais dura. Em "Como é bom! Cantai" (1867) aparece o sentimento de morrer por amor, típico da geração romântica, que se repete em "Luctas d'alma!" (1867). O desejo, quando não encontra possibilidade de realização, "se transforma em veneno" (GREENBLATT, 2011, 143). O rompimento definitivo e o próprio movimento da relação se materializam nos versos de "Fatalidade" (1868): “Disse ao verme da terra águia celeste/ Dóe-me ver-te no pó; minh'alma é nobre;/ Porque não ousas remontar-te ás nuvens?" / "não tenho azas," responde o pobre (...)/ É assim que ao abysmo tormentoso/ Meigo sorriso um coração arrasta,/ E na borda fatal do precipício/ Tu recúas, e eu?... sumo-me. Basta...” (BARRETO, 1903, p. 270).

Hermes Lima esclareceu os motivos do rompimento: "Mas a oposição da família de Leocádia acabou cortando a Tobias toda a esperança de casamento, porque ele era pobre mestiço" (LIMA, 1957, p. 12). A frustração de não poder se casar com sua paixão o levou a descrer da capacidade intelectual que o distinguira: “Até então, pudera vencer as dificuldades com trabalho e tenacidade. Agora, porém, era um obstáculo irremovível, em que se concretizavam distinções sociais ligadas a preconceitos de raça, cor e posição, que se lhe opunha. Destas distinções sempre tivera o pressentimento e elas, desde cedo, concorrem para marcar-lhe a personalidade com o azedume, o pessimismo e a agressividade, que a caracterizam" (LIMA, 1957, p. 12). Por fim, chegou ao limite de pensar em suicídio (LIMA, 1957, p. 12). No ano seguinte, encontraríamos o poeta superado da desilusão amorosa:

\footnotetext{
Graças à exuberância de temperamento, à sua prodigiosa seiva, à fantasia, à capacidade criadora de imaginação, prontamente se refazia dos sofrimentos, derrotas e humilhações. Seus estados de alma sucediam-se com a rapidez das mutações no céu tropical. Da melancolia mais profunda, do ceticismo mais displicente passava às expansões mais calorosas. Sua atividade pontilhava-se de ímpetos e recuos. Aos transportes de entusiasmo sucediam-se crises de depressão. Silvio Romero viu-o, muitas vezes, rir e chorar como uma criança, entregue ao drama da própria sensibilidade (LIMA, 1957, p. 13).
}

Mas, por que a sensibilidade da própria existência abandonara a escrita poética em detrimento do pensamento filosófico? ${ }^{9}$ Seria a desilusão amorosa a chave para essa inflexão na vida de Tobias, já que "desde 1870 que, abandonado quase totalmente à

\footnotetext{
${ }^{9}$ Em carta de 6 de agosto de 1880, Tobias, ao apresentar sua produção textual a Carvalho Lima Júnior, afirma que: "Também tenho, além de versos que publicara em jornais nos tempos acadêmicos, muitas outras produções inéditas, todas do gênero lírico. Nunca senti grandes desejos de publicar livros de versos. Os que possuo, entretanto, dariam para dois ou três volumes". Do espólio dos escritos de Tobias administrado após sua morte pela sua família, por Artur Orlando e Sílvio Romero, não temos informações sobre esses poemas (BARRETO, 2012, p. 224).
} 
poesia, atirou-se à crítica em seus variados ramos, e mais tarde ao direito" (ROMERO, 1980, p. 1189)? Aparentemente não, já que se casa em 1869: "Algum tempo antes [de voltar para o interior após concluir o curso de Direito no Recife] de bacharelar-se, Tobias se casara com uma filha do Coronel João Félix, liberal festejado de 1848, proprietário de vários engenhos no município de Escada. Tudo indica que ele pusera a esperança de grandes vantagens sociais neste casamento. $\mathrm{O}$ sogro prometera-lhe muitas coisas, inclusive um dote" (ROMERO, 1980, p. 19). As promessas não se verificam a ponto de Tobias declarar após a morte do sogro: "Mentira a sua nobreza de caráter, como foi mentira tudo que ele me disse e prometeu, exceto uma só verdade que até hoje me tem compensado dessas mentiras: a minha mulher" (BARRETO, 1963, p. 19).

Certamente, a dedicação à ciência jurídica e à filosofia, que passam gradativamente a sobreporem a poesia (ao menos no contexto de defesa da ideia de ciência), está relacionada ao status social dos bacharéis no Império e sua pretensão de ascensão social. Como ressalta Sérgio Buarque de Holanda: "A boa formação intelectual, o cultivo do espírito, a ilustração real, não simplesmente ostentosas, podem ter alguma importância, mas não é decisiva. $\mathrm{O}$ essencial é saber impor-se, ao menos por um conjunto de qualidades que não pareçam resultar de penoso aprendizado, e é o que garante a coloração aristocrática dessa sociedade" (HOLANDA, 2008, p. 379). Tobias sintetizara o tipo ideal de jurista do Oitocentos: orador potente, polemista profícuo, esclarecido nos trópicos, embora, inegavelmente, não lhe facilitou a ascensão econômica ${ }^{10}$, já que o sergipano morre na penúria.

Mas, para onde fora o poeta sentimental e amoroso que rendera palavras tão calorosas a uma paixão estridente? Segundo Hermes Lima, não apenas a desilusão amorosa mudara a feição de Tobias. Após dez anos em Escada, "a experiência de um longo convívio direto com o 'pais real', que, decerto, ele não teria se tivesse seguido uma carreira de burocrata ou se tivesse vindo para o oficialismo da Côrte. Esta experiência torna-o um cético do liberalismo romântico e literário" (LIMA, 1957, p. 26). Essa experiência da província edifica o poeta e orador popular. Uma outra imagem reiterada pelos biógrafos de Tobias Barreto é a capacidade do intelectual em tocar os corações dos ouvintes. Segundo Beviláqua, que, ao lado de Romero, é um dos maiores

\footnotetext{
${ }^{10}$ A ponderação de Sérgio Buarque, certamente, não se aplica por completo a Tobias, já que este morrera na miséria: "O diploma e canudo de bacharel são naturalmente o complemento e a insígnia de tais virtudes [palavra fácil, reposta pronta, locução ágil ou brilhante], e numa sociedade pretensamente democrática ainda conservam muito prestígio antigo dos brasões de nobreza, dando ao portador uma dignidade e importância que lhe permitam atravessar a vida inteira com discreta compostura, libertando-o da necessidade de uma caça incessante aos bens materiais" (HOLANDA, 2008, p. 379).
} 
responsáveis pela divulgação das ideias e obras de Tobias, esse domínio da palavra falada era característica de Tobias:

\begin{abstract}
O poeta era um impressionista de alma ardente, cujo sensorio vibrava ao mais leve attricto, enxergando sempre o objecto da excitação atravez de um poderoso vidro de au-gimento. A linguagem com que traduzia sua emoção esthetica era sempre imaginosa, ora ungida por um lyrismo suave e delicado, como na poesia- $\mathrm{O}$ beija flor, ora tocada por uns certos tons bruscos e inesperados que trahiam, no pensar de Sylvio Romero, a ardente natureza de mestiço, que era Tobias como Gonçalves Dias e tantos' outros insignes brazileiros. A fórma poetica que melhor se adaptava com a modalidade de seu sentir era a hugoana, a que elle deu realce, depois de José Bonifacio e ao lado de Castro Alves e Palhares, sendo acompanhados, esses corypheus dá poesia condoreira, por Castro Rebello, Joaquim de Souza e outros. As exaltações e os exageros do grande vate francez assim como a doçura magica de sua lyrica cheia de vivacidade e brilho amolda-vam-se à alma poetica do preclaro sergipano como uma tunica talhada sobre ella (BEVILÁQUA, 1897, p. 108109).
\end{abstract}

Ainda que as construções grandiosas e os excessos de Romero, muitas vezes, turvam a compreensão mais apurada da obra de Tobias, essas construções discursivas carregadas de um peso retórico são fundamentais para o entendimento das significações que circularam sobre a obra e as ideias de Tobias em conjunto, constituindo toda uma mitologia sobre seus atos, como veremos. Outro crítico da obra de Tobias, Luiz Pinto Ferreira, analisa a força da oratória do mestre referencial da Escola do Recife com riqueza de detalhes:

O mulato feio, desgracioso, transformava-se na arguição e nos debates do concurso. Os seus olhos flamejavam, da sua boca escancarada, roxa, imóvel, saia uma voz maravilhosa, de múltiplos timbres, a sua gesticulação transbordante, porém sempre expressiva e completando o pensamento. O que êle dizia era novo, profundo, sugestivo. Abria uma nova época na inteligência brasileira, e nós recolhiamos a nova semente, sem saber como ela frutificaria em nossos espíritos, mas seguros de que por ela nos transformáva-mos (FERREIRA, 1954, p. 41).

Outro ápice na trajetória do poeta orador, e que lhe dará fama, ocorre em 1877. Vivendo na cidade de Escada, Tobias Barreto fundara um Club Popular. O discurso de fundação foi publicado no Jornal do Recife com o título "Um discurso em mangas de camisa". Acompanhemos a narração do próprio Tobias:

Em setembro de 1877, appareceu-me a idéa de organisar nesta cidade, e á semelhança de outros, já algures existentes, um pequeno Club Popular. Como todas as lembranças infelizes, que no nosso paiz têm a propriedade de germinar com a mesma rapidez do alho plantado em noute de S. João, segundo crença vulgar, - a minha idéa promptamente grelou; mas também, com a mesma promptidão, murchou e morreu. Foi esta ainda uma das muitas illusões, de que se tem alentado o meu espirito nesta bella terra, onde aliás 
vim sepultar os dous mais caros objetos do meu coração e da minha phantasia: - minha Mãe e meu futuro!...

Foi ainda uma illusão, sem duvida, porém um pouco mais duravel, um pouco menos enganadora do que, por exemplo, a realidade das flores, com a sua vida de um só dia: - minha illusão durou quinze (BARRETO, 1926, p. 97 98).

Síntese de uma marca no percurso biográfico do sergipano, o fracasso em provocar o movimento em uma pequena cidade do interior se soma a outras experiências limite realizadas por Tobias Barreto - como a produção do jornal Deutscher Kampfer. Seu poder de convencimento pela oratória eloquente encontrava limites práticos nas tentativas de subjetivação, assim que planejava uma realidade maior que a possível de ser reverberada na província. Nas palavras do orador Tobias: "A musa que me inspira nesta occasião é muito modesta, para que me obrigue a trajar a grande gala da linguagem bordada a ouro, e muito menos á ouro francez. Alguma cousa de familiar, alguma cousa de designavel por um discurso em mangas de camisa, é o que vos venho apresentar" (BARRETO, 1926, p. 100). Da parte de seus principais comentadores, Tobias fora um eloquente orador, diversas vezes exultado por plateias tanto na assembleia quanto no exercício de seu curto mandato de deputado provincial e ainda como professor na Faculdade de Direito do Recife. No "Discurso em Mangas de Camisa”, a tensão evidente é a antinomia entre liberdade e igualdade e ainda que, curiosamente, faça referência breve A Miséria da Filosofia de Marx ${ }^{11}$. A tese que defende é, justamente, a do confronto entre as liberdades individuais e os poderes políticos que engessavam o exercício dessas liberdades nas pequenas cidades e vilas do Brasil Monárquico. Para Antonio Candido, no Discurso em Mangas de Camisa: "O orador fala em nome do povo, numa pequena cidade encravada em latifúndios açucareiros, onde não se coloca praticamente o problema burguês. Mas pensa no país inteiro" (CANDIDO, 1988, p. 122).

O final do século reluzia novas ideias ${ }^{12}$. A presença da ciência - ou ao menos de uma ideia e discurso que proclamava a ciência - era cada vez mais forte e invadia a vida cultural brasileira, paralelamente, às transformações de nossas estruturas sociais e econômicas arcaicas, especialmente, o Império e a escravidão, que passaram a

\footnotetext{
${ }^{11}$ Tobias chega a ser indicado como o primeiro ou, pelo menos, um dos primeiros brasileiros a ter contato com as ideias de Karl Marx.

${ }^{12}$ A sensação de novidade recebeu ainda a alcunha de "surto de ideias novas", movimento de contestação das ideias filosóficas vigentes da época, especialmente, o ecletismo e o tomismo. Cf: GOMES, Sônia Raimunda. Surto de Idéias Novas - década de 1868-1878: aspectos fundamentais. Dissertação de Mestrado em Filosofia. Programa de Pós-Graduação em Filosofia da Universidade Gama Filho (UGF), Rio de Janeiro, 1986.
} 
representar toda sorte de atrasos frente ao mundo dito civilizado. De qualquer forma, a análise de sua escrita poética demonstra que o lugar secundário que o sergipano fora relegado em nossa literatura, visto que o julgamento sobre o melhor de suas ideias e de sua produção intelectual se encontram no campo do direito e da filosofia para a maioria dos analistas de sua obra, estava preconizado nos versos finais de "Presentimento" (1867), então, criação do jovem estudante de Direito rotulado e estigmatizado por muitos como mestiço, provinciano e rebelde:

Meu Deus!... não posso caminhar sosinho Por entre as sombrar que esta vida encerra, Minha alma anciosa quer voar da terra, Deixai esta ave procurar seu ninho. No pó que habíto não terei as rosas, As doces preces que os felizes têm; Pobres hervinhas brotarão viçosas, E o esquecimento brotará tambem (BARRETO, 1903, p. 54.) 


\section{REFERÊNCIAS}

ABBAGNANO, Nicola. Dicionário de filosofia. 5. Ed. São Paulo: Martins Fontes, 2007.

ALBUQUERQUE JÚNIOR, Durval Muniz de. A invenção do Nordeste e outras artes. 4. Ed. São Paulo: Cortez, 2009.

BARRETO, Tobias. Estudos alemães. Organização: Luiz Antonio Barreto. Rio de Janeiro: J. E. Solomon; Aracaju: Editora Diário Oficial, 2012.

BARRETO, Tobias. Dias e Noites. Publicação posthuma dirigida por Sylvio Roméro. Rio de Janeiro: Laemmert \& Cia., 1903.

BARRETO, Tobias. Discursos. (Obras Completas IV). Aracaju: Edição do Estado do Sergipe, 1926.

BEVILAQUA, Clovis. Juristas Philosophos. Recife: Livraria Magalhães, 1897.

BOSI, Alfredo. História Concisa da Literatura Brasileira. 44. ed. São Paulo: Cultrix, 2007.

CANDIDO, Antonio. O método crítico de Sílvio Romero. São Paulo: Editora da Universidade de São Paulo, 1988.

FERREIRA, Luiz Pinto. Atualidade de Tobias Barreto. Revista da Faculdade de Direito do Ceará. Fortaleza, vol. VIII, 1954.

FREYRE, Gilberto. Casa Grande \& Senzala: formação da família brasileira sob o regime da economia patriarcal. 52. Ed. São Paulo: Global, 2013.

GINZBURG, Carlo. O fio e os rastros: verdadeiro, falso, fictício. São Paulo: Companhia das Letras, 2007.

GREENBLATT, Stephen. Como Shakespeare se tornou Shakespeare. São Paulo: Companhia das Letras, 2011.

HARDMAN, Francisco Foot. Antigos Modernistas. In: NOVAES, Adauto (org.). Tempo e História. São Paulo: Companhia das Letras, 1992.

HOLANDA, Sérgio Buarque. História Geral da Civilização Brasileira. Tomo II: $O$ Brasil Monárquico. Vol. 7: do Império à República. 8. ed. Rio de Janeiro: Bertrand Brasil, 2008.

LIMA, Hermes. Tobias Barreto (a época e o homem). Segunda Edição. São Paulo: Companhia Editora Nacional, 1957.

MACHADO, Roberto. O nascimento do trágico: de Schiller a Nietzsche. Rio de Janeiro: Jorge Zahar Editor, 2006. 
MERCADANTE, Paulo. Tobias Barreto e a cultura brasileira. Paulo Mercadante. In: O pensamento de Tobias Barreto. Colóquio. Lisboa, 4 a 7 de julho de 1990. Universidade Nova de Lisboa: Lisboa, 1991.

OLIVEIRA, Lucia Lippi. Vargas, os intelectuais e as raízes da Ordem. In: D'ARAUJO, Maria Celina (org.). As instituições da Era Vargas. Rio de Janeiro: EdUERJ; Ed. FGV, 1999.

ROMERO, Sílvio. História da Literatura Brasileira. Contribuições e Estudos Gerais para o Exato Conhecimento da Literatura Brasileira. (4 ${ }^{\circ}$ Volume). 7.ed. Rio de Janeiro: Instituto Nacional do Livro, 1980. 